\title{
Ether Extract of Fetal Calf Serum Protects Cultured Rat Cortical Neurons against Glutamate Cytotoxicity
}

\author{
Toshiaki Kume ${ }^{1}$, Hanae Kohchiyama ${ }^{1}$, Hiroyuki Nishikawa ${ }^{1}$, Takehiko Maeda ${ }^{1}$, Shuji Kaneko ${ }^{1}$, \\ Akinori Akaike ${ }^{1, *}$, Naoki Noda ${ }^{2}$ and Tetsuro Fujita ${ }^{3}$

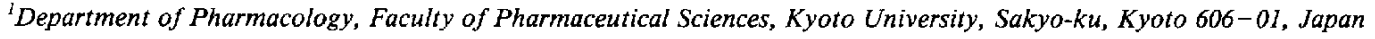 \\ ${ }^{2}$ Department of Chemistry of Natural Products and ${ }^{3}$ Department of Pharmaceutical Manufacturing Chemistry, \\ Faculty of Pharmaceutical Sciences, Setsunan University, Hirakata 573-01, Japan
}

Received February 26, 1997 Accepted March 11, 1997

\begin{abstract}
The effects of an ether extract of fetal calf serum (EE-FCS) on glutamate-induced cytotoxicity were examined using primary cultures of rat cortical neurons. The simultaneous addition of EE-FCS and glutamate reduced glutamate cytotoxicity in a concentration-dependent manner. EE-FCS also reduced the cytotoxicity induced by $S$-nitrosocysteine, a nitric oxide (NO) donor. The findings indicate that EE-FCS contains lipid-soluble, non-peptide substances with neuroprotective actions against NO-mediated glutamate neurotoxicity.
\end{abstract}

Keywords: Fetal calf serum, Glutamate, Nitric oxide

The neurotoxicity of glutamate is associated with a wide range of neurological disorders including hypoxicischemic brain injury $(1,2)$. In cultured cortical neurons, glutamate induces $\mathrm{Ca}^{2+}$ influx via $N$-methyl-D-aspartate (NMDA) receptors and triggers formation of nitric oxide (NO). NO diffuses to adjacent cells, resulting in the appropriated physiological responses and glutamate-related cell death. Thus, NO is regarded as a key substance in NMDA-receptor-mediated glutamate neurotoxicity in the cerebral cortex $(3,4)$. In search of endogenous substances that protect against glutamate neurotoxicity, we found that the conditioned medium of the striatal cultures (CM) reduced glutamate neurotoxicity. Moreover, fetal calf serum (FCS), contained in CM, also reduced glutamate neurotoxicity. This finding led us to investigate the neuroprotective action of FCS. We report here the protective effect of an ether extract of FCS (EE-FCS) in cultured cortical neurons against glutamate cytotoxicity and reduction of cytotoxic action of NO.

Primary cultures were obtained from the cerebral cortex and the striatum of fetal rats (17-19 days of gestation). The procedures have been described previously $(5-7)$. Cortical cultures were incubated in Eagle's minimal essential salt medium (MEM) supplemented with $10 \%$ heat-inactivated FCS (1-7 days after plating)

\footnotetext{
* To whom correspondence should be addressed.
}

or $10 \%$ heat-inactivated horse-serum ( $8-12$ days after plating), glutamine ( $2 \mathrm{mM})$, glucose (total of $11 \mathrm{mM}$ ), $\mathrm{NaHCO}_{3}(24 \mathrm{mM})$, and HEPES $(10 \mathrm{mM})$ at $37^{\circ} \mathrm{C}$ in a humidified $5 \% \mathrm{CO}_{2}$ atmosphere. Striatal cultures were maintained with the medium containing $10 \%$ FCS. After 6 days of plating, non-neuronal cells were removed by addition of $10 \mu \mathrm{M}$ cytosine arabinoside. Only mature (10-12 days in vitro) cultures were studied. All experiments were performed in Eagle's MEM at $37^{\circ} \mathrm{C}$. Cell viability was assessed by means of trypan blue exclusion. Over 200 cells per coverslip were counted to determine the viability. In each experiment, cells on 5 coverslips were counted to obtain means \pm S.E.M. of the cell viability. The statistical significance of the data was determined by Dunnett's two-tailed test. Drugs used were FCS (JRH Biosciences, Lenexa, KS, USA), (+)-MK-801 hydrogen maleate (MK-801; Research Biochemicals Co., Natic, MA, USA) and monosodium glutamate (Nacalai Tesque, Kyoto). $S$-Nitrosocysteine (SNOC) was prepared as previously described (8).

Sixty milliliters of $\mathrm{CM}$ was obtained by incubating striatal cultures (about $2 \times 10^{8}$ cells when plated) in the medium containing $10 \% \mathrm{FCS}$ and $500 \mu \mathrm{M}$ glutamate for $2 \mathrm{hr}$, and then it was lyophilized, dissolved in a small volume of $1 \%$ acetic acid and used for chromatography over a Sephadex G-25 column or for ether extraction. Elution by the Sephadex G-25 column was performed to 
remove ingredients with small molecules such as glutamate. For column chromatography, lyophilized CM was redissolved in $1 \%$ acetic acid in a volume of $3 \mathrm{ml}$ and applied to the Sephadex G-25 column $(17 \times 2 \mathrm{~cm})$. The column was eluted with $1 \%$ acetic acid with the elution velocity of $3 \mathrm{ml} /$ tube. While monitoring the elution pattern by ultraviolet absorbance at $280 \mathrm{~nm}, 3-\mathrm{ml}$ fractions were collected (total of 5 fractions). Neuroprotective activity was investigated in fractions $2-4$, which corresponded to the 5 th -7 th tubes obtained from the gel filtration chromatography (Fig. 1A). For ether extraction, CM and FCS were extracted with the same volume of ether. Then the dried extracts were dissolved in a small amount of ether and added to $2.5 \mathrm{ml}$ of incubation medium. The medium was then incubated at $37^{\circ} \mathrm{C}$ for $1 \mathrm{hr}$ to vaporize ether. Such a treatment of the medium with ether alone did not affect glutamate cytotoxicity. For the bioassay of the ether extracts, $6 \mathrm{ml}$ ether extract of $\mathrm{CM}$ (EE-CM), $1 \mathrm{ml}$ EE-FCS and $10 \mathrm{ml}$ EE-FCS contained ether-soluble ingredients of FCS at the original volume of 6,1 and $10 \mathrm{ml}$, respectively.

A 1 -hr exposure to glutamate $(500 \mu \mathrm{M})$ induced a significant reduction in the viability of cortical cultures but not in that of striatal cultures. Glutamate exposure must exceed $4 \mathrm{hr}$ to observe significant cytotoxicity in striatal cultures (7). Figure 1A summarizes protective effects of CM against glutamate cytotoxicity. For samples eluted with column chromatography, significant reduction of glutamate cytotoxicity was observed with fraction 2 but not with fractions 3 and 4 . For the sample eluted with ether, $6 \mathrm{ml}$ EE-CM markedly reduced glutamate cytotoxicity with an activity similar to that of $1 \mu \mathrm{M}$ MK-801, a NMDA-receptor antagonist. Thus, the study was focused on the non-peptide and hydrophobic components.

As we found in pilot studies that EE-FCS also possessed neuroprotective activity, though weaker than that of EE-CM, we assumed that EE-FCS contains neuroprotective substances with properties similar to that of EE-CM. Figure 2 shows examples of protective effects of EE-FCS against the cyototoxicity induced by glutamate and SNOC which spontaneously releases NO. A 1-hr exposure of the cortical cultures to either $500 \mu \mathrm{M}$ glutamate or $100 \mu \mathrm{M}$ SNOC markedly increased the number of cells stained by trypan blue (Fig. 2, $\mathrm{Ab}$ and $\mathrm{Bb}$ ). Concomitant addition of $10 \mathrm{ml}$ EE-FCS with either glutamate or SNOC reduced the number of cells stained by trypan blue (Fig. 2, Ac and Bc). As shown in Fig. 1B, 1-hr exposure to 10 $\mathrm{ml} \mathrm{EE-FCS} \mathrm{alone} \mathrm{did} \mathrm{not} \mathrm{affect} \mathrm{cell} \mathrm{viability,} \mathrm{but} \mathrm{EE-FCS}$ reduced glutamate cytotoxicity in a concentration-dependent manner. Moreover, $10 \mathrm{ml}$ EE-FCS significantly reduced SNOC cytotoxicity (Fig. 1C).

Both EE-FCS and EE-CM protected cultured cortical neurons against glutamate cytotoxicity. As EE-CM was more potent than the samples of CM eluted by Sephadex
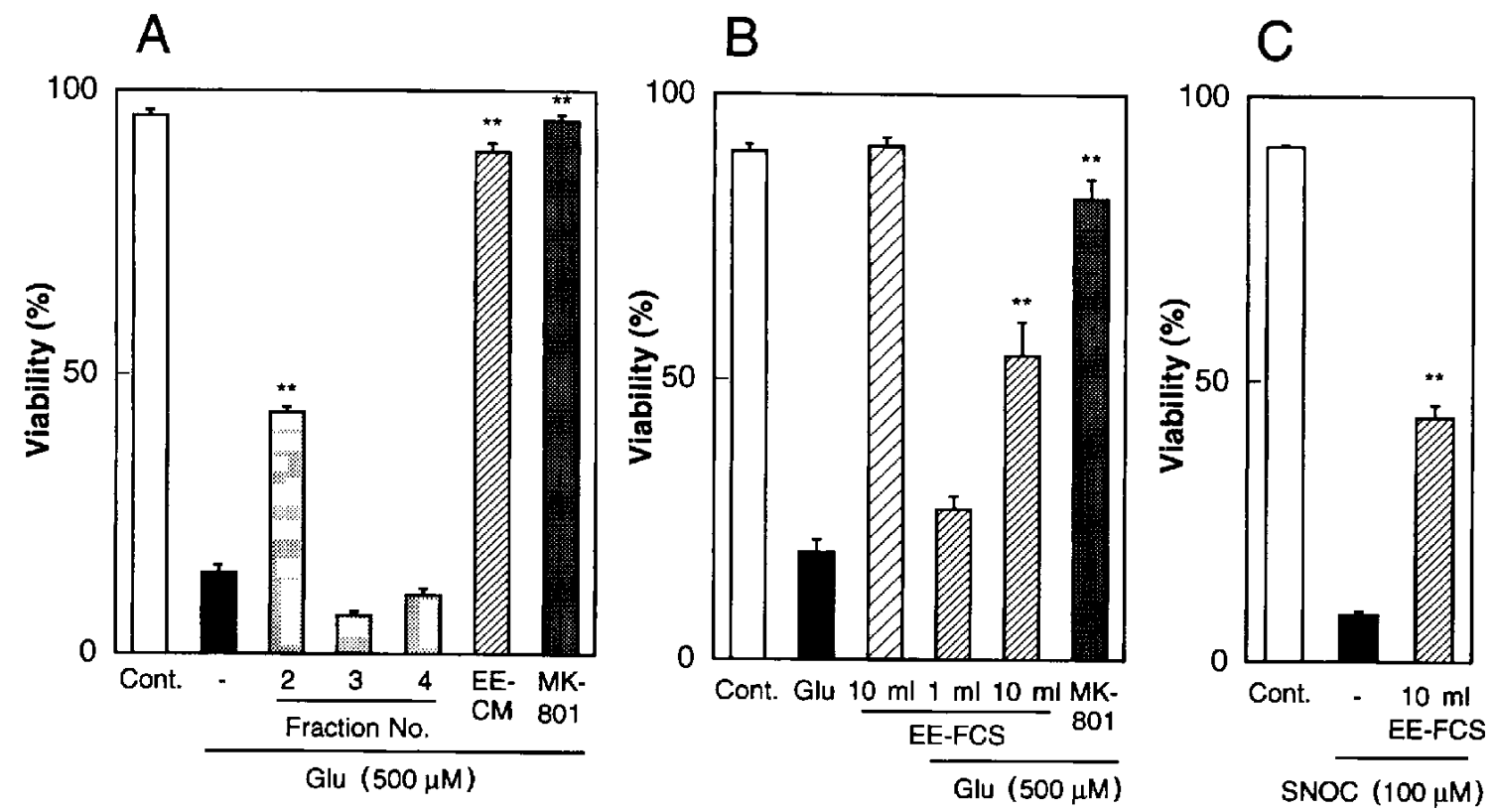

Fig. 1. Effects of the conditioned medium of the striatal cultures (CM) and the fetal calf serum (FCS) on cytotoxicity induced by glutamate (Glu) and $S$-nitrosocysteine (SNOC) in cultured cortical neurons. Cultures were exposed to either glutamate or SNOC for $1 \mathrm{hr}$. Samples eluted with the Sephadex column (Fractions No. 2-4), $6 \mathrm{ml}$ ether extract of CM (EE-CM), MK-801 $(1 \mu \mathrm{M})$, and 1 and $10 \mathrm{ml}$ ether extract of FCS (EE-FCS) were added to glutamate-containing or SNOC-containing medium. Cont.: control (non-treated cultures). ${ }^{* *} \mathrm{P}<0.01$, compared with glutamate-treated group (A and B) or SNOC-treated group (C). 

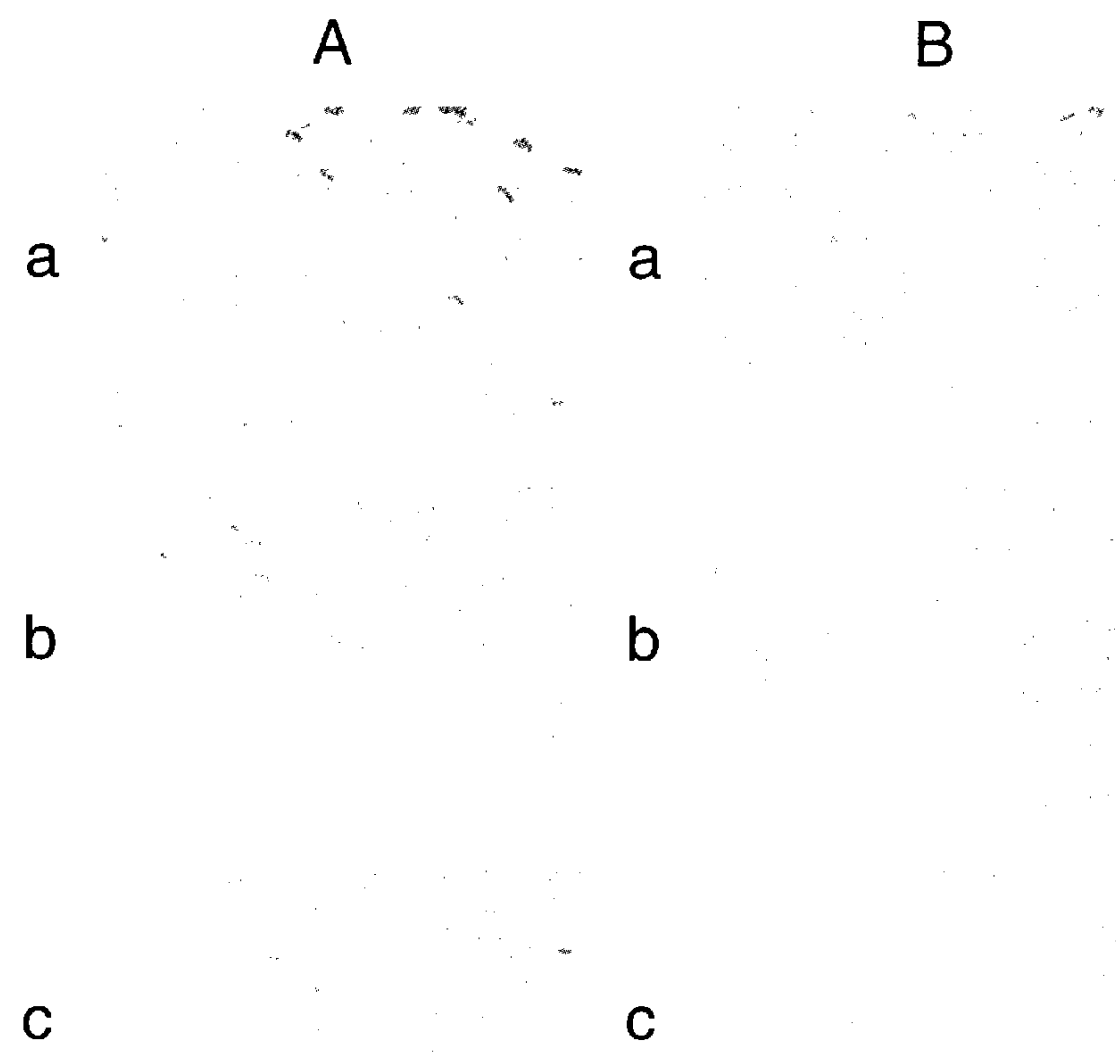

$50 \mu m$

Fig. 2. Effects of ether extract of fetal calf serum (EE-FCS) on cytotoxicity induced by glutamate (A) and $S$-nitrosocysteine (SNOC, B). Cultures were exposed to either glutamate $(500 \mu \mathrm{M})$ or SNOC $(100 \mu \mathrm{M})$ for $1 \mathrm{hr}$. EE-FCS was added to glutamate-containing medium. Culture fields were photographed after trypan blue staining followed by formalin fixation. Aa and $\mathrm{Ba}$ indicate the non-treated cells (control). $\mathrm{Ab}$ and $\mathrm{Bb}$ show glutamate- and SNOC-treated cells, respectively. $\mathrm{Ac}$ and $\mathrm{Bc}$ shows cells treated with $10 \mathrm{ml}$ EE-FCS plus glutamate and cells treated with $10 \mathrm{ml}$ EE-FCS plus SNOC, respectively.

column, the study was focused on the ether extract. Concomitant application of EE-FCS with glutamate significantly reduced glutamate cytotoxicity, indicating that EE-FCS contains substances possessing inhibitory actions on the cascade starting from NMDA-receptor stimulation. Because it prevented the cytotoxicity of an NO donor, the neuroprotective action of EE-FCS is at least partly due to its ability to reduce NO-mediated cytotoxicity. This activity resembled those of brain-derived neurotrophic factor and vitamin $B_{12}$ analogs, although these substances prevented glutamate cytotoxicity only after chronic application $(9,10)$. Further studies are required to isolate neuroprotective substances from EE-FCS.

\section{Acknowledgments}

This study was supported in part by a Grant-in-Aid for Scientific Research and that on priority areas from the Ministry of Education,
Science, Sports and Culture, Japan. We thank Dr. Shun Shimohama (Department of Neurology, Faculty of Medicine, Kyoto University) for his generous advice.

\section{REFERENCES}

1 Choi DW: Calcium-mediated neurotoxicity: relationship to specific channel types and role in ischemic damage. Trends Neurosci 11, 465-469 (1988)

2 Meldrum B and Garthwaite J: Excitatory amino acid neurotoxicity and neurodegenerative disease. Trends Pharmacol Sci 11, $379-387$ (1990)

3 Dawson VL, Dawson TM, London ED, Bredt DS and Snyder SH: Nitric oxide mediates glutamate neurotoxicity in primary cortical cultures. Proc Natl Acad Sci USA 88, 6368-6371 (1991)

4 Akaike A, Tamura Y, Terada K and Nakata N: Regulation by neuroprotective factors of NMDA receptor mediated nitric oxide synthesis in the brain and retina. Prog Brain Res 103, 


$$
391-403 \text { (1994) }
$$

5 Akaike A, Tamura Y, Sato Y, Ozaki K, Matsuoka R, Miura S and Yoshinaga T: Cholecystokinin-induced protection of cultured cortical neurons against glutamate neurotoxicity. Brain Res 557, 303-307 (1991)

6 Akaike A, Kaneko S, Tamura Y, Nakata N, Shiomi H, Ushikubi $\mathbf{F}$ and Narumiya S: Prostaglandin $\mathrm{E}_{2}$ protects cultured cortical neurons against $N$-methyl-D-aspartate receptor-mediated glutamate cytotoxicity. Brain Res 663, 237-243 (1994)

7 Amano T, Ujihara H, Matsubayashi H, Sasa M, Yokota T, Tamura $Y$ and Akaike A: Dopamine-induced protection of striatal neurons against kainate receptor-mediated glutamate cytotoxicity in vitro. Brain Res 655, 61-69 (1994)
8 Kashii S, Mandai M, Kikuchi M, Honda Y, Tamura Y, Kaneda $\mathrm{K}$ and Akaike A: Dual actions of nitric oxide in $N$-methyl-Daspartate receptor-mediated neurotoxicity in the cultured retinal neurons. Brain Res 711, 93-101 (1996)

9 Kume T, Kouchiyama H, Kaneko S, Maeda T, Kaneko S, Akaike A, Shimohama S, Kihara T, Kimura J, Wada $\mathrm{K}$ and Koizumi S: BDNF prevents NO mediated glutamate cytotoxicity in cultured cortical neurons. Brain Res (in press)

10 Akaike A, Tamura Y, Sato Y and Yokota T: Protective effects of a vitamin $B_{12}$ analog methylcobalamin against glutamate cytotoxicity in cultured cortical neurons. Eur J Pharmacol 241, $1-6$ (1993) 